\title{
The Use of Coconut Shells for the Removal of Dyes from Aqueous Solutions
}

\author{
Tomasz Jóźwiak, Urszula Filipkowska', Paula Bugajska', Tomasz Kalkowski \\ 1 Department of Environmental Engineering, Faculty of Environmental Sciences, University of Warmia and \\ Mazury in Olsztyn, ul. Warszawska 117, 10-720 Olsztyn, Poland \\ * Corresponding author's e-mail: tomasz.jozwiak@uwm.edu.pl
}

\begin{abstract}
The main purpose of the work was to check the possibility of using coconut shells for the removal of the dyes popular in the textile industry from aqueous solutions. The sorption abilities of an unconventional sorbent were tested against four anionic dyes: Reactive Black 5, Reactive Yellow 84, Acid Yellow 23, Acid Red 18 as well as two cationic dyes: Basic Violet 10 and Basic Red 46. The scope of research included investigation pertaining to the effect of $\mathrm{pH}$ on the effectiveness of sorption of dyes, conducted in order to determine the time of equilibrium of sorption and determine the maximum sorption capacity of coconut shells with respect to pigments. The most favorable $\mathrm{pH}$ of sorption for the anionic dyes and Basic Violet 10 was $\mathrm{pH} 3$ and for Basic Red $46-\mathrm{pH} 6$. The equilibrium time of sorption was the shortest in the case of acidic dyes (Acid Yellow 23/ Acid Red 18 - 45 min), while the longest in the case of alkaline dyes (Basic Red 46 - $90 \mathrm{~min}$, Basic Violet 10 - $180 \mathrm{~min}$ ). The sorption capacity of coconut shells in relation to anionic dyes was for Reactive Black $5-0.82 \mathrm{mg} / \mathrm{g}$, Reactive Yellow $84-0.96 \mathrm{mg} / \mathrm{g}$, Acid Yellow $23-0.53 \mathrm{mg} / \mathrm{g}$ and for Acid Red $18-0.66 \mathrm{mg} / \mathrm{g}$. The tested sorbent showed much higher sorption capacity with respect to the cationic dyes, i.e. Basic Violet $10(28.54 \mathrm{mg} / \mathrm{g})$ and Basic Red $46(68.52 \mathrm{mg} / \mathrm{g})$.
\end{abstract}

Keywords: sorption, coconut shells, anionic dyes, cationic dyes

\section{INTRODUCTION}

The post-production sewage generated in dyeing, textile or paper factories often contains high concentrations of dyes. Due to the low susceptibility of dyes for biodegradation, the decolorization of industrial wastewater with traditional, biological methods of wastewater treatment is usually ineffective [Robinson et al. 2001]. There is a high risk that the colored substances that have not been removed from sewage may enter the natural environment, causing its degradation. The perspective of the environment contaminated by dyes should encourage entrepreneurs to use effective technologies for decolorizing the industrial wastewater.

Currently, the scientific community holds the opinion that sorption is the most economical and the most environmentally friendly method of wastewater decolorization. During the sorption, no toxic intermediates are formed, in contrast to the oxidation methods (ozonation, oxidation with $\mathrm{NaOCl}$ ) [Wijannarong et al. 2013]. Sorption also does not cause sediment formation or sewage salinity, like the precipitation methods do (coagulation and electrocoagulation) [Liang et al. 2014, Nandi and Patel 2013].

Decolorization of sewage by sorption does not require the use of complicated installations, as is the case with membrane methods. The sorption costs and its effectiveness mainly depend on the type of sorbent. The most frequently used sorbents for the decolorization of wastewater are various types of activated carbons. Due to their high price, cheaper substitutes are currently being sought. High hopes are associated with the use of waste materials from the agro-food industry as commonly available alternatives to the commercial sorbents.

The coconut shells are easily available waste material from the food industry. Their popularity, 
which translates into a low price of raw material is the result of wide range of applications of coconut. This paper explores the possibility of using coconut shells for the removal of dyes popular in the textile industry from aqueous solutions.

\section{MATERIALS}

\section{Coconut shells}

Coconuts from coconut palm (Cocos nucifera), originating from the Philippines, were purchased at a local hypermarket in Olsztyn (Poland). Due to the monotypic nature of the Cocos genus, the coconuts available on the market always have a similar composition, regardless of the country of origin. The shells of coconuts usually contain $46 \%$ lignin, 14\% cellulose and 32\% hemicellulose [Cagnon et al. 2009].

\section{Dyes}

Six dyes popular in the textile industry, including 4 anionic and 2 cationic dyes were used in the research. Among the anionic dyes there were 2 reactive dyes (Reactive Black 5, Reactive Yellow 84) and 2 acid dyes (Acid Red 18, Acid Yellow 23). The tested cationic dyes were Basic
Violet 10 and Basic Red 46. The characteristics of the dyes used in this work are summarized in Table 1 .

\section{METHODOLOGY}

The coconut shells were ground in a laboratory grinder and sifted through the sieves with a mesh diameter of $5 \mathrm{~mm}$ and then $3 \mathrm{~mm}$. A 3-5 mm diameter fraction was placed in $2 \mathrm{M} \mathrm{H}_{2} \mathrm{SO}_{4}$. After $24 \mathrm{~h}$, the shells were rinsed with distilled water, then placed in $2 \mathrm{M} \mathrm{NaOH}$ for $24 \mathrm{~h}$. Next, the shells were drained and washed with distilled water (until $\mathrm{pH} \sim 7$ was obtained in the leachate). The coconut shells (CS) were ready for study after drying at $105^{\circ} \mathrm{C}$.

The coconut shells (CS) were weighed in an amount of $1 \mathrm{~g}$ each and added to the series of conical flasks $(250 \mathrm{~mL})$. Then, dye solutions $(10 \mathrm{mg} / \mathrm{L}-100 \mathrm{~mL})$ at $\mathrm{pH} 2-11$ were added to the flasks. Then, the flasks were placed on a laboratory shaker (150 r.p.m.) with vibration amplitude of $25 \mathrm{~mm}$. After $60 \mathrm{~min}$, the samples were taken from the flasks $(10 \mathrm{~mL})$ to determine the concentration of dye in the solution.

$\mathrm{CS}$ in an amount of $10 \mathrm{~g}$ each were weighed and added to the beakers $(1000 \mathrm{~mL})$. Afterwards, the dye solutions $(10 \mathrm{mg} / \mathrm{L}-500 \mathrm{~mL})$ with the

Table 1. Characteristics of dyes used in this work

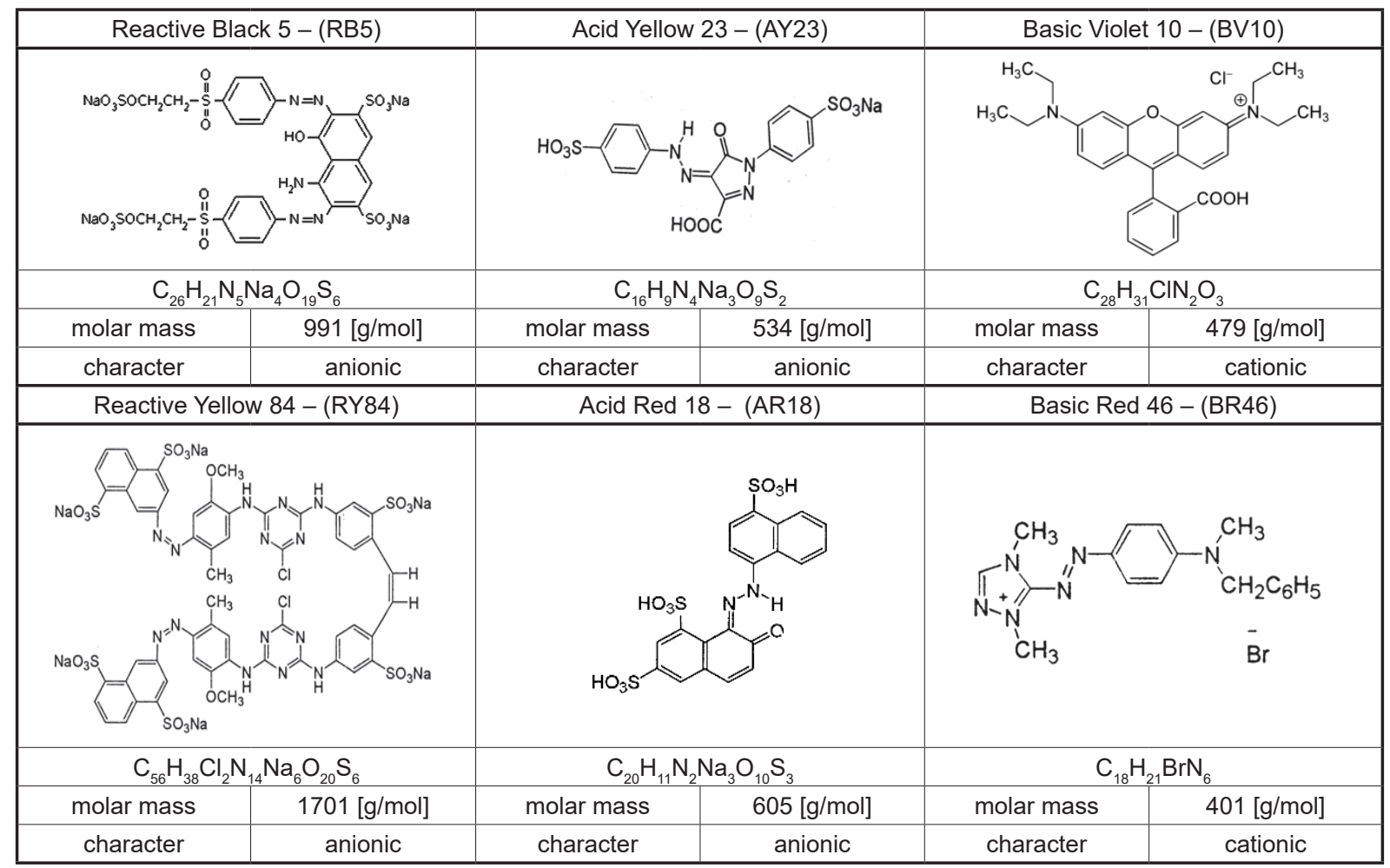


optimum $\mathrm{pH}$, determined in 4.1 were added to the beakers.

Then, the beakers were placed on a magnetic stirrer $(150 \mathrm{rpm})$. During the sorption, samples $(5 \mathrm{~mL})$ were taken from the solutions at specified intervals to determine the dye concentration.

CS (1 g) were weighed and added to the conical flasks $(250 \mathrm{~mL})$. Next, dye solutions $(100 \mathrm{~mL})$ with optimal $\mathrm{pH}$, determined in 4.1., with conc. $5-50 \mathrm{mg} / \mathrm{L}$ (anionic dyes) or $10-500$ $\mathrm{mg} / \mathrm{L}$ (cationic dyes) were added to the flasks and then the flasks were placed on a laboratory shaker (150 r.p.m.). After the sorption time determined in 4.2, the samples $(10 \mathrm{~mL})$ were taken from the flasks to determine the concentration of the dye remaining in the solution.

The amount of dye adsorbed on the sorbent was calculated from the equation 1 :

$$
\mathrm{Q} s=\frac{(\mathrm{Co}-\mathrm{Cs}) \cdot \mathrm{V}}{\mathrm{m}}
$$

Three sorption isotherms were used to determine the sorption capacity of CS: Langmuir (2), Langmuir 2 (Langmuir double isotherm) (3) and Freundlich (4).

$$
\begin{gathered}
\mathrm{Qs}=\frac{\mathrm{q}_{\max } \cdot \mathrm{K}_{\mathrm{c}} \cdot \mathrm{C}}{1+\mathrm{K}_{\mathrm{c}} \cdot \mathrm{C}} \\
\mathrm{Qs}=\frac{\mathrm{b}_{1} \cdot \mathrm{k}_{1} \cdot \mathrm{C}}{1+\mathrm{k}_{1} \cdot \mathrm{C}}+\frac{\mathrm{b}_{2} \cdot \mathrm{k}_{2} \cdot \mathrm{C}}{1+\mathrm{k}_{2} \cdot \mathrm{C}} \\
\mathrm{Qs}=\mathrm{K} \cdot \mathrm{C}^{\mathrm{n}}
\end{gathered}
$$

where: $Q_{s}-$ mass of the sorbed dye $[\mathrm{mg} / \mathrm{g}]$

$C_{o}-$ initial dye concentration $[\mathrm{mg} / \mathrm{L}]$

$C_{s}$ - concentration of dye after sorption $[\mathrm{mg} / \mathrm{L}]$

$V$ - volume of the solution [L]

$m$ - mass of the sorbent [g.d.m.]

$q_{\max }-$ maximum sorption capacity in the Langmuir equation $[\mathrm{mg} / \mathrm{g}]$

$K_{c}$ - constant in the Langmuir equation

[L/mg]

$C$ - concentration of dye remaining in solution $[\mathrm{mg} / \mathrm{L}]$

$b_{1} ; b_{2}-$ maximum capacity of active sites

(type I and II) $[\mathrm{mg} / \mathrm{g}]$

$k_{1} ; k_{2}-$ constants in the Langmuir 2 equation $[\mathrm{L} / \mathrm{mg}]$

$K$ - constant of sorption equilibrium in Freundlich model

$n$ - parameter of heterogeneity [-]

\section{RESULTS AND DISCUSSION}

The effect of $\mathrm{pH}$ on the effectiveness of dye sorption

The sorption effectiveness of reactive dyes RB5 and RY84 on the tested sorbent was the highest at $\mathrm{pH} 2$ and decreased with the increasing $\mathrm{pH}$ of the solution, obtaining the lowest value at $\mathrm{pH}$ 11. The maximum decrease in the sorption efficiency of RB5 and RY84 was found in the $\mathrm{pH}$ range 2-4 (Fig. 1a,d).

The decrease of the sorption efficiency of reactive dyes, together with the increase in $\mathrm{pH}$, has also been confirmed in the sorption studies of RB5 and RY84 on compost [Jóźwiak et al. 2013], chitosan sorbents [Filipkowska and Jóźwiak 201] wheat bran [Annadurai et al. 2002] and modified starches [Wang et al. 2010].

As in the case of reactive dyes, the sorption effectiveness of acid dyes on CS was decreased with the increasing $\mathrm{pH}$ of the solution. The effect of $\mathrm{pH}$ increase on the reduction of binding efficiency of AY23 and AR18 was most evident in the narrow $\mathrm{pH}$ range 2-3. (Fig. 1b,e). At $\mathrm{pH} 11$, the sorption of AY23 and AR18 on CS practically did not occur. A very similar tendency was also observed in the studies on AY23 and AR18 sorption on sawdust [Shokoohi et al. 2010].

The increased sorption efficiency of anionic dyes at low $\mathrm{pH}$ results from the change in surface charge of the sorbent. Probably, in the low $\mathrm{pH}$, functional groups present in the CS structure $(-\mathrm{OH})$ are protonated, owing to which the sorbent gains a positive charge. The sorbent, which has a positive charge, attracts the anionic electrostatic dyes, supporting their sorption. The interaction between the dye and the nut shell is the stronger the lower the $\mathrm{pH}$ of the solution (Fig. 1a,b,d,e).

The sorption efficiency of BV10 on the CS was the highest at $\mathrm{pH} 3$ and decreased with the increasing $\mathrm{pH}$. The biggest decrease in the sorption efficiency of BV10 was found in the range of $\mathrm{pH} 3-5$, and in the range of $\mathrm{pH} 8-11$ (Fig. 1c). The effectiveness of BR46 sorption at the initial $\mathrm{pH}$ range of 2-6 was increased along with $\mathrm{pH}$, obtaining the highest value at $\mathrm{pH} 6$. A further increase in $\mathrm{pH}$ in the $\mathrm{pH}$ range $6-8$ decreased the binding efficiency of RB46 on the tested sorbent. A characteristic feature of BR46 solutions is decolorization at $\mathrm{pH}>8$. For this reason, the effectiveness of BR46 sorption at $\mathrm{pH}$ 9-11 has not been included in the graph (Fig. 1f). 

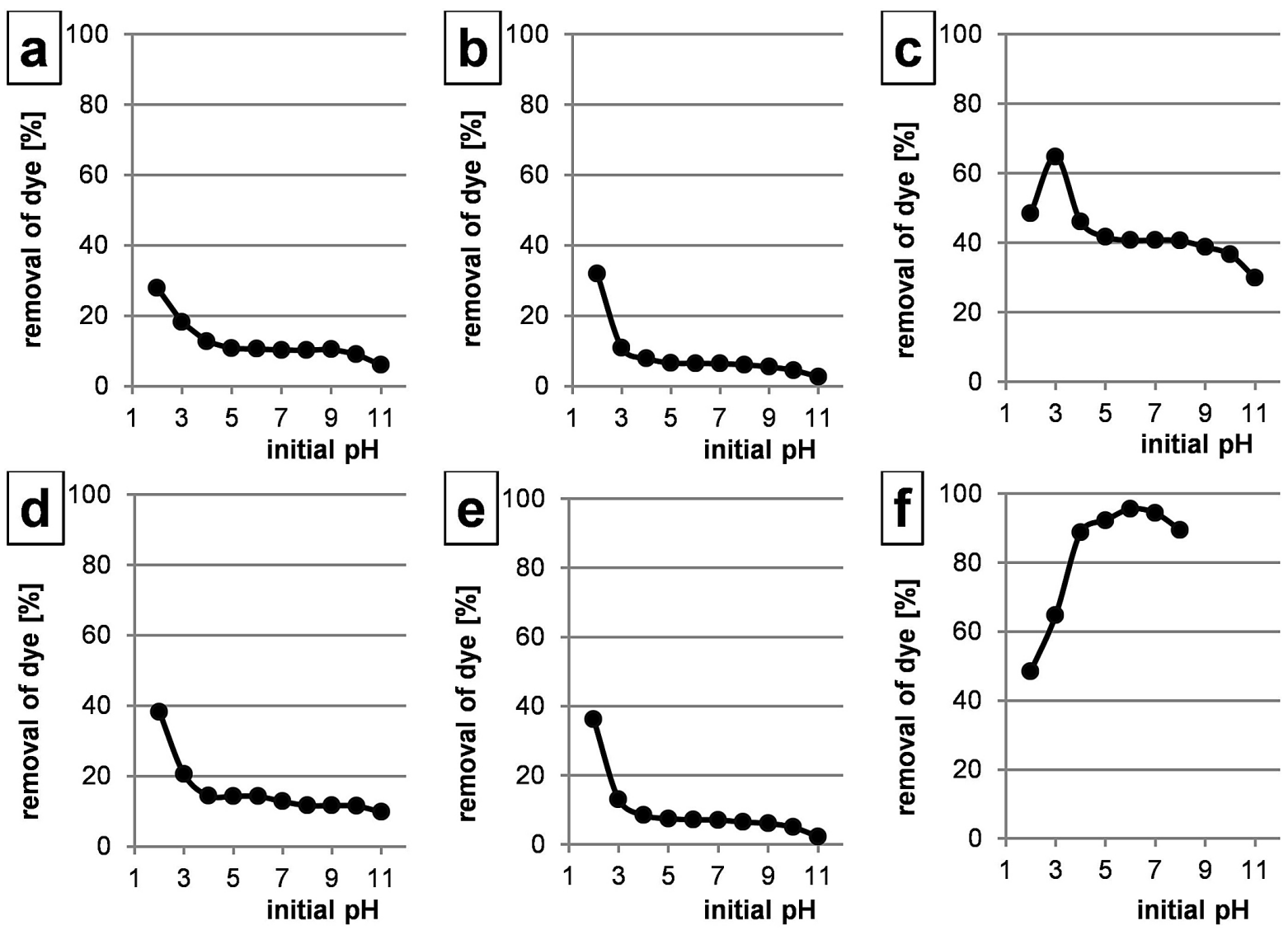

Fig. 1. The effect of $\mathrm{pH}$ on the effectiveness of sorption of dyes on CS: a) RB5, b) AY23, c) BV10, d) RY84, e) AR18, f) BR46

The differences between the optimal $\mathrm{pH}$ of sorption of BV10 and BR46 may result from the presence of a carboxylic functional group in the BV10 structure. Generating a local negative charge, the $-\mathrm{COOH}$ group $\left(-\mathrm{COO}^{-}+\mathrm{H}^{+}\right)$caused that under certain conditions, at low $\mathrm{pH}, \mathrm{BV} 10$ behaved like anionic dyes. Because BR46 does not have anionic functional groups, its sorption at low $\mathrm{pH}$ was ineffective.

\section{Determination of the equilibrium time of sorption}

For reactive dyes RB5 and RY84, irrespective of the initial concentration of the dye, the equilibrium time of sorption was 60 min (Fig. 2 a, d). The highest intensity of sorption of dyes was noted in the first phase of the process.

Similar time of sorption of reactive dyes on biosorbents was obtained in the studies on sorbtion of RB5 on cotton seed shells (60 min) [Uçar et al. 2012] and rapeseed stems (60 min) [Hamzeh et al. 2012].

The equilibrium time of sorption of AR18 and AY23 acid dyes on the tested sorbent was
45 min (Fig. 2b, e). Similarly to the sorption of reactive dyes, the intensity of acid dye binding was highest in the first phase of sorption. The shorter time to obtain the sorption equilibrium of AR18 and AY23 with respect to RB5 and RY84 could result from the lower molar mass of acid dyes, compared to reactive dyes. Presumably, smaller sizes of acid dye molecules allowed them to penetrate into more difficultly available sorption centers located in the deeper layers of the sorbent in a shorter time.

The equilibrium time of sorption of cationic dyes on CS was longer than in the case of anionic dyes. For BR46, the sorption equilibrium was obtained after 90 min of sorption (Figure 2f). The same equilibrium time was also established in the research on Basic Red 46 sorption on pine needles [Deniz and Karaman 2011], as well as fir sawdust [Laasri et al. 2007].

Out of the tested dyes, the longest time of CS sorption, equaling $180 \mathrm{~min}$, was obtained by BV10 (Figure 2c). The BV10 sorption equilibrium time, in comparison to BR46, may have resulted from its higher molar mass and the presence of the - $\mathrm{COO}^{-}$group in the BV10 structure. 

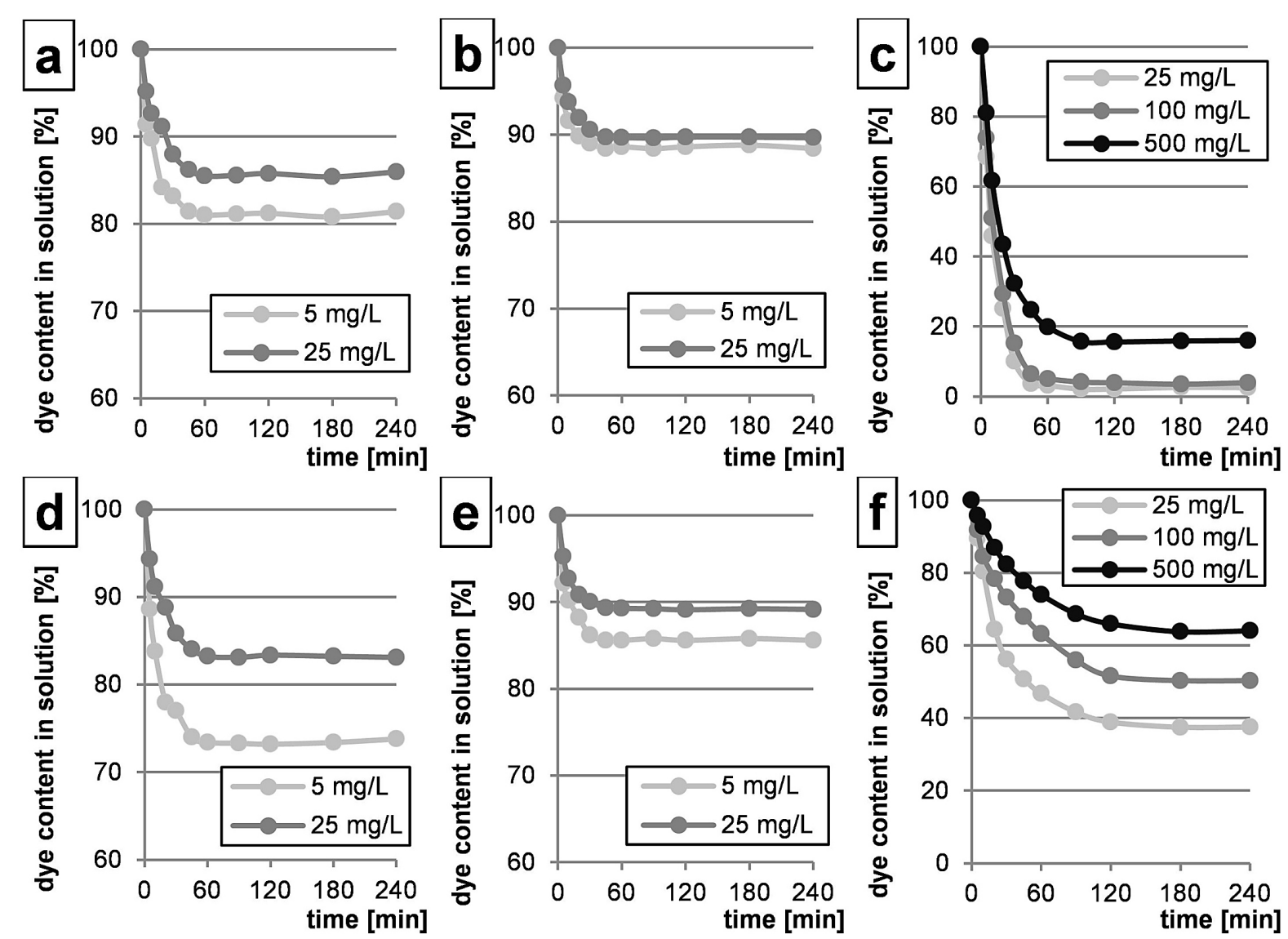

Fig. 2. Percent changes in the concentration of dyes: a) RB5, b) AY23, c) BV10, d) RY84,

e) AR18, f) BR46 during sorption using CS as a sorbent

The sorption equilibrium time level of 180 min was also obtained in the studies on Basic Violet 10 sorption on coffee grounds [Shen and Gondal 2013], as well as the leaves of A. nilotica [Santhi et al. 2014].

\section{Sorption capacity}

On the basis of the coefficient of determination $\left(\mathrm{R}^{2}\right)$, it was established that the Langmuir isotherm and the Langmuir double isotherm describe the sorption of CS dyes better than the Freundlich isotherm (Table 2).

In the case of sorption of anionic dyes on $\mathrm{CS}$, the constants determined from the Langmuir and Langmuir 2 isotherm $\left(\mathrm{Q}_{\max }, \mathrm{K} / \mathrm{K}_{\mathrm{c}}, \mathrm{R}^{2}\right)$ obtain identical values. This may suggest the presence of only one type of sorption center for anionic dyes on CS. The discussed type of sorption center may be a small amount of the displaced hydroxyl groups of polysaccharides and lignins contained in the sorbent.

In turn, the sorption of cationic dyes on CS is better described by the Langmuir 2 isotherm. This probably indicates the possibility of occurrence on the sorbent of at least two types of active sites relative to cationic dyes. Presumably, the sorption centers may be the primary and secondary hydroxyl groups of cellulose, hemicellulose and lignin, contained in the CS structure.

The sorption capacity of CS in relation to reactive dyes RB5 and RY84 was $0.82 \mathrm{mg} / \mathrm{g}$ and $0.96 \mathrm{mg} / \mathrm{g}$. In the case of acid dyes, the obtained sorption capacity was lower and for AY23 and AR18 it was $0.53 \mathrm{mg} / \mathrm{g}$ and $0.66 \mathrm{mg} / \mathrm{g}$, respectively (Table 2). The values of $\mathrm{K}_{c}$ constants denoting the degree of dye affinity for the sorbent for all anionic dyes are similar.

CS sorbs the reactive dyes more efficiently than the acidic dyes, because RB5 and RY84 have reactive functional groups. The vinyl sulfone group RB5 or the chlorotriazine group RY84 could support the sorption of dyes on CS by chemisorption.

The repeatedly tested sorbent showed a higher sorption capacity with respect to cationic than anionic dyes. CS in the amount of $1 \mathrm{~g}$ was able to bind $28.54 \mathrm{~g} \mathrm{BV} 10$ or $68.52 \mathrm{~g}$ BR46 (Table 2). 
Table 2. Constants designated from the isotherms: (Langmuir, Langmuir 2 and Freundlich)

\begin{tabular}{|c|c|c|c|c|c|c|c|}
\hline & & \multicolumn{6}{|c|}{ DYE } \\
\hline $\begin{array}{c}\text { Models } \\
\text { (izotherms) }\end{array}$ & $\begin{array}{c}\text { Constants } \\
\text { in sorption model }\end{array}$ & RB5 & RY84 & AY23 & AR18 & BV10 & BR46 \\
\hline \multirow{3}{*}{ Langmuir } & $\mathrm{Q}_{\max }[\mathrm{mg} / \mathrm{g}$ s.m.] & 0.819 & 0.962 & 0.526 & 0.661 & 25.825 & 49.426 \\
\hline & $\mathrm{K}_{\mathrm{c}}$ [l/g s.m.] & 0.035 & 0.038 & 0.043 & 0.030 & 0.007 & 0.059 \\
\hline & $\mathrm{R}^{2}$ & 0.992 & 0.975 & 0.938 & 0.981 & 0.994 & 0.976 \\
\hline \multirow{6}{*}{ Langmuir 2} & $Q_{\max }[\mathrm{mg} / \mathrm{g}$ s.m.] & 0.819 & 0.962 & 0.526 & 0.661 & 28.544 & 68.515 \\
\hline & $\mathrm{b}_{1}$ [mg/g s.m.] & 0.413 & 0.481 & 0.263 & 0.330 & 1.994 & 54.031 \\
\hline & $\mathrm{k}_{1}[\mathrm{~L} / \mathrm{mg}]$ & 0.035 & 0.038 & 0.043 & 0.030 & 0.086 & 0.015 \\
\hline & $\mathrm{b}_{2}$ [mg/g s.m.] & 0.406 & 0.481 & 0.263 & 0.331 & 26.550 & 14.484 \\
\hline & $\mathrm{k}_{2}[\mathrm{~L} / \mathrm{mg}]$ & 0.035 & 0.038 & 0.043 & 0.030 & 0.005 & 0.378 \\
\hline & $\mathrm{R}^{2}$ & 0.992 & 0.975 & 0.938 & 0.981 & 0.996 & 0.993 \\
\hline \multirow{3}{*}{ Freundlich } & $\mathrm{K}[-]$ & 0.057 & 0.072 & 0.045 & 0.039 & 0.816 & 6.102 \\
\hline & n [L/g s.m.] & 0.581 & 0.569 & 0.544 & 0.606 & 0.547 & 0.457 \\
\hline & $\mathrm{R}^{2}$ & 0.979 & 0.957 & 0.894 & 0.965 & 0.986 & 0.981 \\
\hline
\end{tabular}

The sorption of cationic dyes on the tested sorbent was promoted by its acidic nature, which was explained in section 4.1.

The $\mathrm{k} 1$ and $\mathrm{k} 2$ constants determined from the Langmuir 2 model indicate a higher affinity of BR46 for the sorbent compared to BV10. Lower sorption capacities of the tested sorbent with respect to BV10 may result from the greater weight of the dye as well as the presence of a carboxyl group that generates a strong local negative charge.

\section{CONCLUSIONS}

The sorption effectiveness of dyes on CS depends on the type of dye. The effectiveness of sorption on the tested sorbent characterizing the cationic dyes is many times higher than that of anionic dyes.

The condition for obtaining satisfactory results of dye sorption is the correction of the $\mathrm{pH}$ of the solution in which the sorption takes place. The sorption efficiency of anionic dyes is the highest in the $\mathrm{pH}$ range $2-3$. Optimal $\mathrm{pH}$ of the sorption of cationic dyes should be determined individually for each dye.

The Equilibrium time of dye sorption on CS depends on the type of dyes. The sorption equilibrium time for CS increases in the following series: acidic dyes $<$ reactive dyes $<$ cationic dyes (BR46 <BV10). The equilibrium time may be influenced by: the nature of the dye, its molar mass and functional groups.

Probably, CS have only one type of active site relative to anionic dyes. Relative to cationic dyes, CS presumably have at least two types of sorption centers.

\section{Acknowledgements}

This study was financed under Project No. 18.610.008-300 of the University of Warmia and Mazury in Olsztyn, Poland.

\section{REFERENCES}

1. Annadurai G., Juang R.S., Lee D.J. 2002. Use of cellulose-based wastes for adsorption of dyes from aqueous solutions. Journal of Hazardous Materials, 92, 263-274.

2. Cagnon B., Py X. Guillot A., Stoeckli F., Chambat G. 2009. Contributions of hemicellulose, cellulose and lignin to the mass and the porous properties of chars and steam activated carbons from various lignocellulosic precursors. Bioresource Technology, 100, 292-298.

3. Deniz F., Karaman S. 2011. Removal of Basic Red 46 dye from aqueous solution by pine tree leaves. Chemical Engineering Journal, 170, 67-74 .

4. Filipkowska U., Jóźwiak T. 2013. Application of chemically-cross-linked chitosan for the removal of Reactive Black 5 and Reactive Yellow 84 dyes from aqueous solutions. Journal of Polymer Engineering, 33, 735-747.

5. Hamzeh Y., Ashori A., Azadeh E., Abdulkhani A. 2012. Removal of Acid Orange 7 and Remazol Black 5 reactive dyes from aqueous solutions using a novel biosorbent. Materials Science and Engineering: C, 32, 1394-1400.

6. Jóźwiak T., Filipkowska U., Rodziewicz J., Mielcarek A., Owczarkowska, D. 2013). Zastosowanie 
kompostu jako taniego sorbentu do usuwania barwników z roztworów wodnych. Annual Set The Environment Protection, 15, 2398-2411.

7. Laasri L., Elamrani M.K., Cherkaoui O. 2007. Removal of two cationic dyes from a textile effluent by filtration-adsorption on wood sawdust. Environmental Science and Pollution Research, 14, 237-240.

8. Liang C.Z., Sun S.P., Li F.Y., Ong Y.K., Chung T.S. 2014. Treatment of highly concentrated wastewater containing multiple synthetic dyes by a combined process of coagulation/flocculation and nanofiltration. Journal of Membrane Science, 469, 306-315.

9. Nandi B.K., Patel S. 2013. Effects of operational parameters on the removal of brilliant green dye from aqueous solutions by electrocoagulation. Arabian Journal of Chemistry, 10 (S2), 2961-2968.

10. Robinson T., McMullan G., Marchant R., Nigam P. 2001. Remediation of dyes in textile effluent: a critical review on current treatment technologies with a proposed alternative. Bioresource Technology, 77, 247-255.

11. Santhi T., Prasad A.L., Manonmani S. 2014. A comparative study of microwave and chemically treated Acacia nilotica leaf as an eco friendly adsorbent for the removal of rhodamine B dye from aqueous solution. Arabian Journal of Chemistry, 7, 494-503.

12. Shen K., Gondal M.A. 2013. Removal of hazardous Rhodamine dye from water by adsorption onto exhausted coffee ground. Journal of Saudi Chemical Society, 21, 120-127

13. Shokoohi R., Vatanpoor V., Zarrabi M., Vatani A. 2010. Adsorption of Acid Red 18 (AR18) by Activated Carbon from Poplar Wood - A Kinetic and Equilibrium Study. E-Journal of Chemistry, 7, 65-72.

14. Uçar D., Armağan B. 2012. The removal of reactive black 5 from aqueous solutions by cotton seed shell. Water Environment Research, 84, 323-327.

15. Wang Z., Xiang B., Cheng R., Li Y. 2010. Behaviors and mechanism of acid dyes sorption onto diethylenetriamine-modified native and enzymatic hydrolysis starch. Journal of Hazardous Materials, 183, 224-232.

16. Wijannarong S. Aroonsrimorakot S., Thavipoke P., Kumsopa C., Sangjan S. 2013. Removal of Reactive Dyes from Textile Dyeing Industrial Effluent by Ozonation Process. APCBEE Procedia, 5, 279-282. 